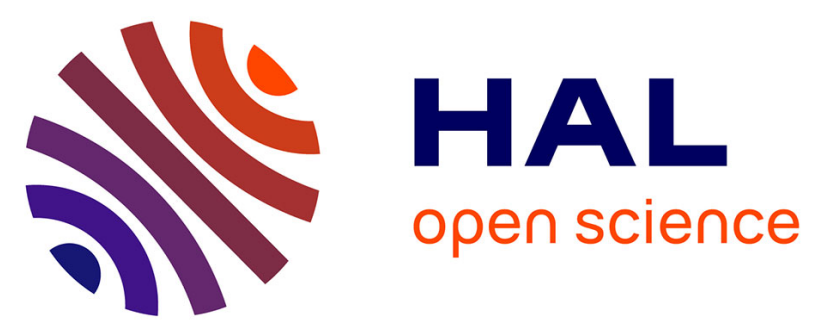

\title{
Loading of Silica Nanoparticles in Block Copolymer Vesicles during Polymerization-Induced Self-Assembly: Encapsulation Efficiency and Thermally Triggered Release
}

Charlotte J. Mable, Rebecca R. Gibson, Sylvain Prevost, Beulah E. Mckenzie, Oleksandr O. Mykhaylyk, Steven P. Armes

\section{To cite this version:}

Charlotte J. Mable, Rebecca R. Gibson, Sylvain Prevost, Beulah E. Mckenzie, Oleksandr O. Mykhaylyk, et al.. Loading of Silica Nanoparticles in Block Copolymer Vesicles during Polymerization-Induced Self-Assembly: Encapsulation Efficiency and Thermally Triggered Release. Journal of the American Chemical Society, 2015, 137 (51), pp.16098-16108. 10.1021/jacs.5b10415 . hal-01572892

\section{HAL Id: hal-01572892 https://hal.science/hal-01572892}

Submitted on 8 Aug 2017

HAL is a multi-disciplinary open access archive for the deposit and dissemination of scientific research documents, whether they are published or not. The documents may come from teaching and research institutions in France or abroad, or from public or private research centers.
L'archive ouverte pluridisciplinaire HAL, est destinée au dépôt et à la diffusion de documents scientifiques de niveau recherche, publiés ou non, émanant des établissements d'enseignement et de recherche français ou étrangers, des laboratoires publics ou privés. 


\title{
Loading of Silica Nanoparticles in Block Copolymer Vesicles during Polymerization-Induced Self-Assembly: Encapsulation Efficiency and Thermally Triggered Release
}

\author{
Charlotte J. Mable, ${ }^{* \dagger}{ }^{\dagger}$ Rebecca R. Gibson, ${ }^{\dagger}$ Sylvain Prevost, ${ }^{\ddagger}$ Beulah E. McKenzie,
} Oleksandr O. Mykhaylyk, ${ }^{* \dagger}$ and Steven P. Armes ${ }^{* \dagger}$

${ }^{\dagger}$ Department of Chemistry, University of Sheffield, Brook Hill, Sheffield, South Yorkshire S3 7HF, United Kingdom

${ }^{\ddagger}$ ESRF, The European Synchrotron, 71 Avenue des Martyrs, 38000 Grenoble, France

\section{Supporting Information}

\begin{abstract}
Poly(glycerol monomethacrylate)-poly(2-hydroxypropyl methacrylate) diblock copolymer vesicles can be prepared in the form of concentrated aqueous dispersions via polymerization-induced self-assembly (PISA). In the present study, these syntheses are conducted in the presence of varying amounts of silica nanoparticles of approximately $18 \mathrm{~nm}$ diameter. This approach leads to encapsulation of up to hundreds of silica nanoparticles per vesicle. Silica has high electron contrast compared to the copolymer which facilitates TEM analysis, and its thermal stability enables quantification of the loading efficiency via thermogravimetric analysis. Encapsulation efficiencies can be calculated using disk
\end{abstract} centrifuge photosedimentometry, since the vesicle density

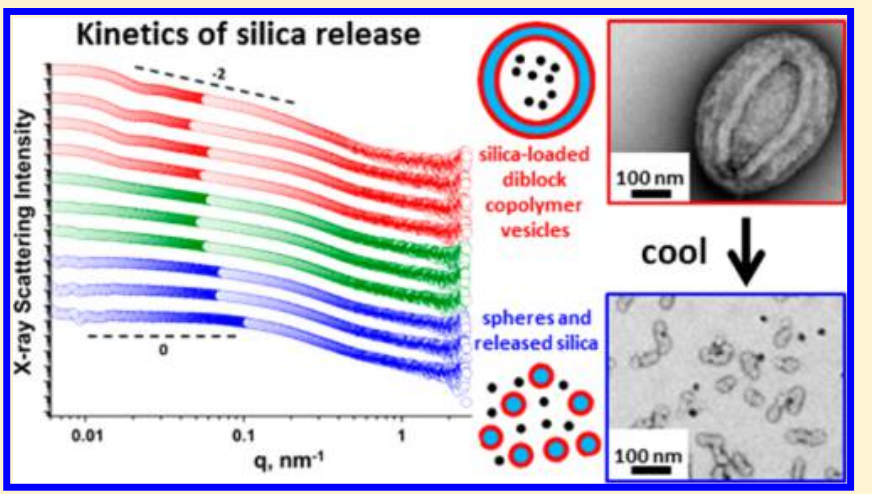
increases at higher silica loadings while the mean vesicle diameter remains essentially unchanged. Small angle X-ray scattering (SAXS) is used to confirm silica encapsulation, since a structure factor is observed at $q \approx 0.25 \mathrm{~nm}^{-1}$. A new two-population model provides satisfactory data fits to the SAXS patterns and allows the mean silica volume fraction within the vesicles to be determined. Finally, the thermoresponsive nature of the diblock copolymer vesicles enables thermally triggered release of the encapsulated silica nanoparticles simply by cooling to $0-10{ }^{\circ} \mathrm{C}$, which induces a morphological transition. These silica-loaded vesicles constitute a useful model system for understanding the encapsulation of globular proteins, enzymes, or antibodies for potential biomedical applications. They may also serve as an active payload for self-healing hydrogels or repair of biological tissue. Finally, we also encapsulate a model globular protein, bovine serum albumin, and calculate its loading efficiency using fluorescence spectroscopy.

\section{INTRODUCTION}

Microcompartmentalization is widely acknowledged to be a fundamental prerequisite for life on Earth. ${ }^{1-4}$ Many intracellular processes require spatial separation of components via impermeable lipid membranes, with membrane proteins allowing the selective diffusion of various chemical species in and out of cells. ${ }^{5}$ Similarly, microencapsulation is important for many industrial formulations, ranging from orally administered drugs $^{6}$ to agrochemicals ${ }^{7,8}$ to laundry products. ${ }^{9,10}$ This enables the controlled release of active components and can also prevent the premature deactivation of mutually incompatible components, such as enzyme denaturation by bleach chemicals in liquid laundry products. In particular, liposomes ${ }^{11}$ and block copolymer vesicles $^{12-19}$ (or "polymersomes") are some of the most widely used carriers in the development of drug delivery applications. $^{20-22}$ Typically, such hollow nanoparticles are loaded with water-soluble drugs, ${ }^{23-25}$ oligonucleotides, ${ }^{25-27}$ enzymes, ${ }^{28}$ or antibodies. ${ }^{29}$ In this context, there are also a few reports describing the incorporation of magnetic nanoparticles within block copolymer vesicle membranes, which may enable active targeting of tumors. ${ }^{30}$

Over the last five years or so, polymerization-induced selfassembly (PISA) has become established as a powerful tool for the rational design and efficient synthesis of a wide range of diblock copolymer nano-objects in either aqueous solution or non-aqueous media. ${ }^{31-33}$ Of particular relevance to the present study, RAFT aqueous dispersion polymerization can be utilized to prepare block copolymer vesicles at copolymer concentrations of up to $25 \% \mathrm{w} / \mathrm{v}$ solids. ${ }^{34-38}$ Periodic sampling during such syntheses has confirmed a progressive evolution in copolymer morphology, with transmission electron microscopy (TEM) studies revealing that the transformation of highly anisotropic worms into well-defined vesicles proceeds via a socalled "jellyfish" intermediate. ${ }^{35}$ These observations suggest an intriguing question: can the efficient encapsulation of nano-

Received: October 5, 2015

Published: November 24, 2015 


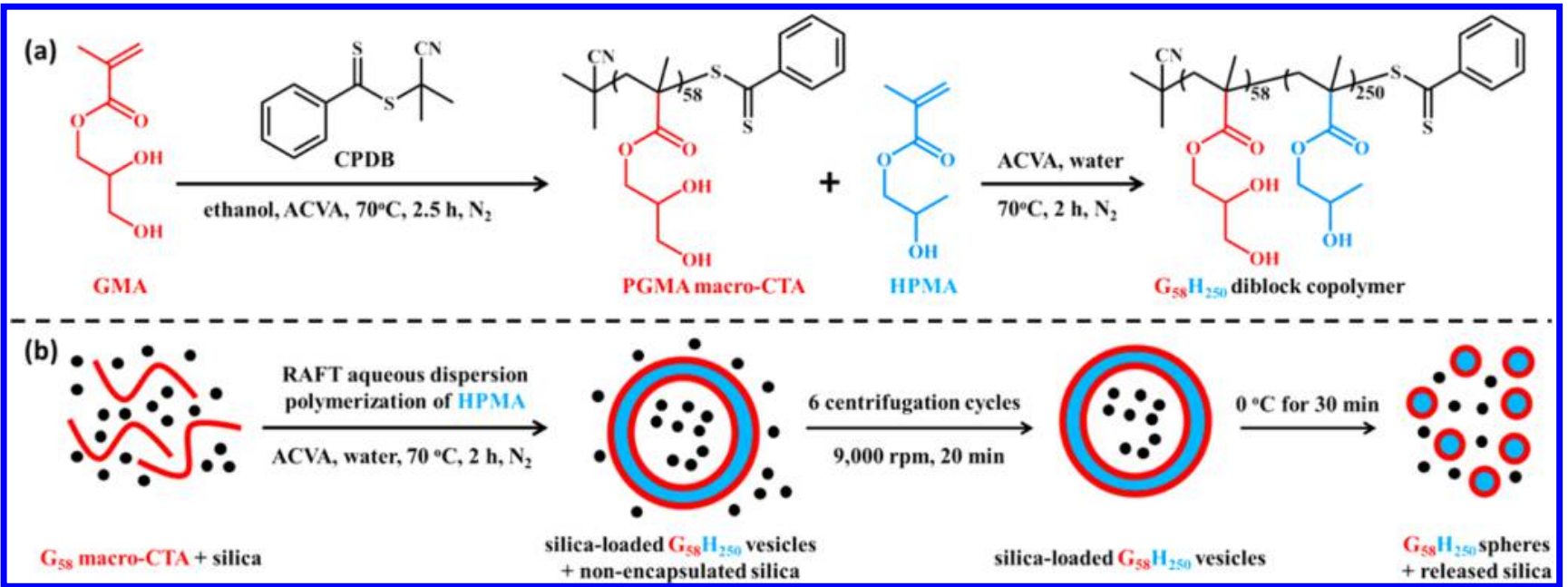

Figure 1. (a) Synthesis of a $\mathrm{G}_{58}$ macro-CTA via RAFT solution polymerization and subsequent synthesis of $\mathrm{G}_{58} \mathrm{H}_{250}$ diblock copolymer via RAFT aqueous dispersion polymerization (targeting this copolymer composition is known to lead to vesicle formation ${ }^{35,36}$ ). (b) Schematic cartoon illustrating in situ encapsulation of silica nanoparticles during the synthesis of $\mathrm{G}_{58} \mathrm{H}_{250}$ diblock copolymer vesicles via RAFT aqueous dispersion polymerization and subsequent release of such silica nanoparticles on cooling to around $273 \mathrm{~K}$, which induces vesicle dissociation.

particles within the vesicles be achieved during such PISA syntheses? ${ }^{39}$ This question is directly addressed herein, with an aqueous silica sol being selected as a model cargo. These nanoparticles were chosen for the following five reasons: (i) they are commercially available in the form of concentrated dispersions; (ii) they possess sufficient electron contrast to allow their visualization by TEM; (iii) they are relatively strong $\mathrm{X}$-ray scatterers; (iv) their density is sufficiently high to enable sedimentation-based particle size analysis; (v) their loading efficiency can be readily determined using thermogravimetry. Moreover, Leibler and co-workers ${ }^{40}$ recently reported that silica nanoparticles enable the convenient repair of cleaved synthetic hydrogels or biological tissue (e.g., organs such as the liver). Hence, such silica nanoparticles are likely to be a biomedically relevant active species, in addition to serving as a model cargo.

In the present study, a series of silica-loaded $\mathrm{AB}$ diblock copolymer vesicles was readily prepared via RAFT aqueous dispersion polymerization ${ }^{36,37,41}$ by chain-extending a watersoluble poly(glycerol monomethacrylate) (PGMA) chain transfer agent (CTA) using 2-hydroxypropyl methacrylate (HPMA) in the presence of varying concentrations of aqueous silica nanoparticles.

Provided that an appropriate diblock copolymer composition is targeted, the resulting amphiphilic PGMA-PHPMA diblock copolymer chains undergo in situ self-assembly via a complex multistep mechanism that ultimately leads to the formation of large polydisperse vesicles. ${ }^{35}$ An open-ended "jellyfish" structure is generated just prior to vesicle formation; ${ }^{35}$ hence, silica nanoparticles can diffuse within the jellyfish before membrane formation is complete, leading to their in situ encapsulation. It is perhaps worth emphasizing that vesicle formation via this pathway circumvents the problem of encapsulation discussed by Adams et al. for vesicles prepared via post-polymerization processing of preformed diblock copolymers. $^{42}$

\section{RESULTS AND DISCUSSION}

Synthesis and Characterization of Silica-Loaded Vesicles. RAFT solution polymerization of GMA was conducted in ethanol at $70{ }^{\circ} \mathrm{C}$ to generate a near-monodisperse $\mathrm{G}_{58}$ macro-CTA $\left(M_{\mathrm{w}} / M_{\mathrm{n}}=1.13\right.$; see Figure $\left.\mathrm{S} 1\right)$. After purification, this water-soluble macro-CTA was utilized for the RAFT aqueous dispersion polymerization of HPMA at $10 \%$ w/w solids (see Figure 1a) to obtain PGMA $_{58}-\mathrm{PHPMA}_{250}$ diblock copolymers, denoted hereafter as $\mathrm{G}_{58} \mathrm{H}_{250}$ for the sake of brevity. Gel permeation chromatography (GPC) studies indicated that near-monodisperse diblock copolymers were obtained with minimal macro-CTA contamination and high blocking efficiencies $\left(M_{\mathrm{w}} / M_{\mathrm{n}}=1.12\right.$; see Figure S1). RAFT aqueous dispersion polymerization of HPMA was also conducted in the presence of $5-35 \% \mathrm{w} / \mathrm{w}$ silica nanoparticles. ${ }^{1} \mathrm{H}$ NMR studies (see Figure S2) indicated that $>99 \%$ HPMA conversion was achieved within $2 \mathrm{~h}$ at $70{ }^{\circ} \mathrm{C}$, regardless of the presence of silica nanoparticles.

TEM images (see Figures 2 and S3) reveal a pure vesicular morphology for the control experiments performed in the absence of any silica nanoparticles, as expected when targeting such an asymmetric $\mathrm{G}_{58} \mathrm{H}_{250}$ diblock copolymer composition. ${ }^{35,36}$ Dynamic light scattering (DLS) studies indicated a mean vesicle diameter of $350 \mathrm{~nm}$ with a polydispersity (PDI) of 0.08 (see Table 1). The folds that are discernible in the TEM images are the result of vesicle buckling and/or partial collapse of these relatively delicate nanostructures under ultrahigh vacuum. For experiments conducted in the presence of silica nanoparticles, TEM images reveal that a pure vesicular morphology is still obtained, with excess non-encapsulated silica nanoparticles also present. In order to remove the nonencapsulated silica, the vesicles were centrifuged at $9000 \mathrm{rpm}$ for $20 \mathrm{~min}$ and redispersed in deionized water (see cartoon in Figure $1 \mathrm{~b}$ ). After six centrifugation-redispersion cycles, TEM images suggest that the vast majority of the non-encapsulated silica is removed and that the remaining silica nanoparticles reside within the vesicles (see Figures 2 and S3).

Hypothetically, these TEM observations could be the result of drying artifacts. In contrast, cryo-TEM allows the direct observation of hydrated vesicles that have not been dried, stained, or fixed; thus, this technique is much more representative of their native environment. Cryo-TEM images (see Figure 3) confirm that the silica nanoparticles are indeed located inside the vesicle lumen. Both DLS and TEM studies indicate that the vesicle diameter is essentially unchanged, regardless of the initial silica concentration, $[\text { silica }]_{0}$. 


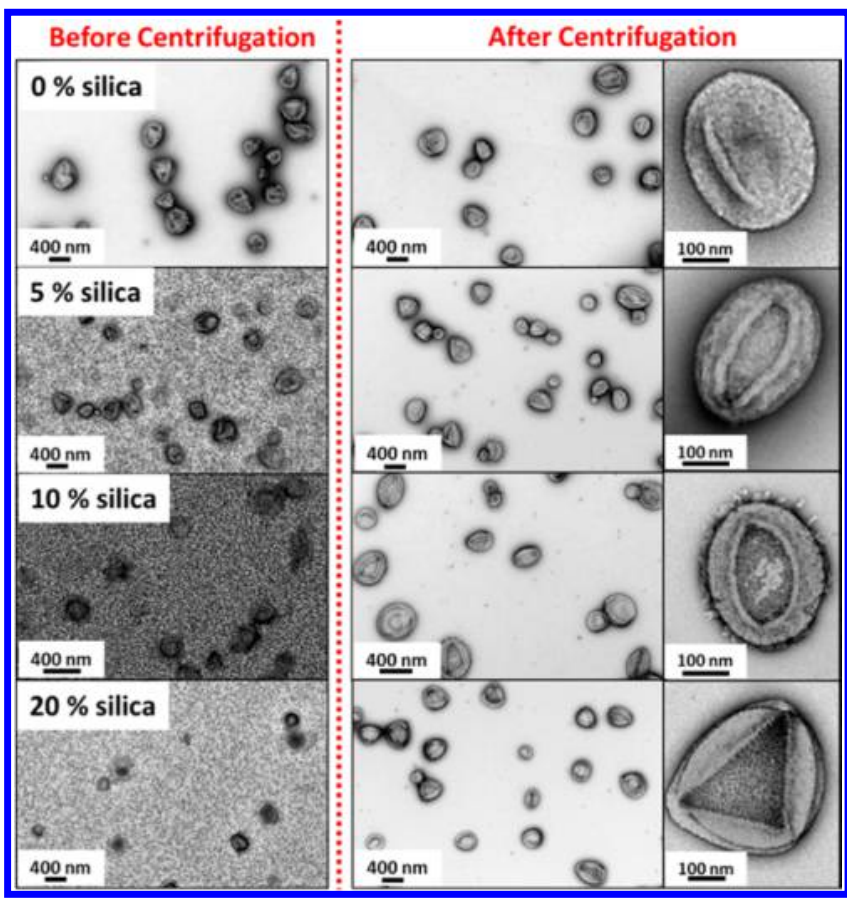

Figure 2. TEM images of $\mathrm{G}_{58} \mathrm{H}_{250}$ diblock copolymer vesicles synthesized in the presence of increasing amounts of silica nanoparticles $(0-20 \% \mathrm{w} / \mathrm{w}$ silica). (Left) As-synthesized dried dispersions containing excess silica. (Right) After six centrifugation-redispersion cycles to remove excess silica. Additional TEM images for silica-loaded vesicles prepared using an initial silica concentration of $15 \%, 25 \%$, $30 \%$, or $35 \% \mathrm{w} / \mathrm{w}$ are shown in Figure S3.

Simple geometric considerations suggest that the maximum number of silica nanoparticles encapsulated per vesicle during these PISA syntheses should be given by the total vesicle lumen volume multiplied by the number of silica nanoparticles per unit volume in the aqueous solution, which depends on $[\text { silica }]_{0}$. In order to quantify the amount of silica encapsulated within the vesicle lumen, the following three characterization techniques were utilized.

Disk Centrifuge Photosedimentometry (DCP). DCP reports the weight-average particle diameter, which lies between the number-average and intensity-average diameters reported by TEM and DLS, respectively. ${ }^{43}$

Assuming a spherical particle morphology, a DCP weightaverage diameter can be calculated, provided that the particle

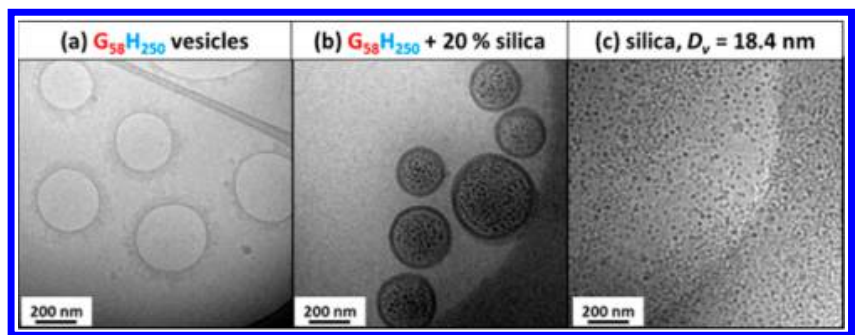

Figure 3. Cryo-TEM images obtained for (a) empty $\mathrm{G}_{58} \mathrm{H}_{250}$ diblock copolymer vesicles, (b) $\mathrm{G}_{58} \mathrm{H}_{250}$ diblock copolymer vesicles prepared in the presence of $20 \% \mathrm{w} / \mathrm{w}$ silica nanoparticles (after centrifugation to remove excess silica nanoparticles), and (c) the silica nanoparticles alone, for which the SAXS-derived vesicle diameter $\left(D_{\mathrm{v}}\right)$ is $18.4 \mathrm{~nm}$.

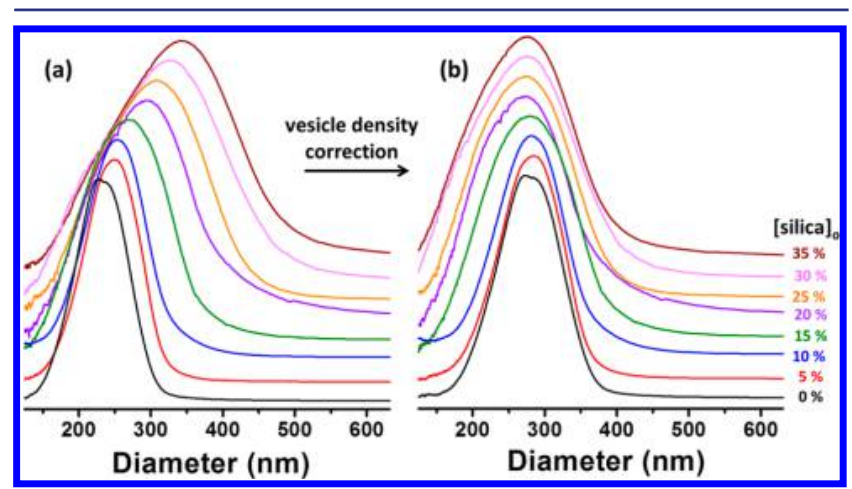

Figure 4. DCP data recorded for $\mathrm{G}_{58} \mathrm{H}_{250}$ diblock copolymer vesicles prepared in the presence of increasing amounts of silica nanoparticles $(0-35 \% \mathrm{w} / \mathrm{w}$ silica). (a) Uncorrected weight-average vesicle size distributions for which an arbitrary vesicle density of $1.10 \mathrm{~g} \mathrm{~cm}^{-3}$ was utilized. (b) Corrected weight-average vesicle size distributions whereby the weight-average diameter was held constant at $291 \mathrm{~nm}$ (as calculated from SAXS analysis of vesicles prepared in the absence of any silica nanoparticles) by adjusting the vesicle density from 1.071 to $1.141 \mathrm{~g} \mathrm{~cm}^{-3}$, see Table 1 . These densities were then used to calculate the silica content of the vesicles. N.B. The apparent broadening of these DCP size distributions is an artifact caused by the superposition of a density distribution on the size distribution (because larger vesicles will contain more silica nanoparticles, see main text for details).

density is accurately known. Since the PHPMA membrane is highly plasticized by water ${ }^{38}$ the vesicle density was estimated to be $1.10 \mathrm{~g} \mathrm{~cm}^{-3}$. When arbitrarily fixing the vesicle density at this value, the mean vesicle diameter increases monotonically and

Table 1. Summary of DLS Hydrodynamic Diameters $\left(D_{h}\right)$, Initial and Final Silica Contents Determined by Thermogravimetry (TGA) Before and After Centrifugation, TGA-Derived Silica Loading Efficiency $\left(L E_{\text {TGA }}\right)$, Effective Density $\left(\rho_{\text {eff }}\right)$, Number of Silica Nanoparticles Per Vesicle $\left(N_{\mathrm{sv}}\right)$, and Encapsulation Efficiency $\left(E E_{\mathrm{DCP}}\right)$ Determined Using Disk Centrifuge

Photosedimentometry (DCP), SAXS-Derived Vesicle Diameter (where $D_{\mathrm{v}}=2 R_{\mathrm{v}}$ and $\sigma_{D v}$ Is Its Standard Deviation), and the Concentration of Encapsulated Silica Obtained for a Series of $\mathrm{G}_{58} \mathrm{H}_{250}$ Diblock Copolymers Prepared in the Presence of 0-35\% w/w Silica

\begin{tabular}{|c|c|c|c|c|c|c|c|c|c|}
\hline $\begin{array}{l}{[\text { silica }]_{0}} \\
(\% \mathrm{w} / \mathrm{w})\end{array}$ & $\begin{array}{c}\text { DLS } D_{\mathrm{h}} \\
(\mathrm{PDI})(\mathrm{nm})\end{array}$ & $\begin{array}{l}\text { initial TGA silica } \\
\text { content }(\%)\end{array}$ & $\begin{array}{l}\text { final TGA silica } \\
\text { content }(\%)\end{array}$ & $\begin{array}{l}L E_{\mathrm{TGA}} \\
(\%)\end{array}$ & $\begin{array}{l}\operatorname{DCP} \rho_{\text {eff }} \\
\left(\mathrm{g} \mathrm{cm}^{-3}\right)\end{array}$ & $\begin{array}{l}\mathrm{DCP} \\
N_{\mathrm{sv}}\end{array}$ & $E E_{\mathrm{DCP}}(\%)$ & $\begin{array}{c}\text { SAXS } D_{\mathrm{v}} \pm \\
\sigma_{\mathrm{Dv}}(\mathrm{nm})\end{array}$ & $\begin{array}{l}\text { SAXS-derived concentration of } \\
\text { encapsulated silica }(\% \mathrm{w} / \mathrm{w})\end{array}$ \\
\hline 0 & $350(0.08)$ & 0.25 & 0.25 & 0.0 & 1.071 & 0 & 0 & $291 \pm 7$ & 0 \\
\hline 5 & $364(0.17)$ & 37.7 & 3.78 & 7.85 & 1.076 & 9 & 13.2 & $296 \pm 6$ & 0.20 \\
\hline 10 & $390(0.18)$ & 51.5 & 8.72 & 9.55 & 1.084 & 24 & 16.9 & $295 \pm 5$ & 0.41 \\
\hline 15 & $317(0.20)$ & 63.5 & 13.6 & 10.5 & 1.093 & 40 & 18.9 & $323 \pm 5$ & 1.12 \\
\hline 20 & $402(0.17)$ & 73.1 & 17.0 & 10.2 & 1.106 & 66 & 24.6 & $335 \pm 6$ & 1.87 \\
\hline 25 & $382(0.15)$ & 78.2 & 19.2 & 9.51 & 1.119 & 91 & 25.6 & $301 \pm 5$ & 1.75 \\
\hline 30 & $410(0.16)$ & 83.8 & 21.0 & 8.85 & 1.130 & 112 & 26.2 & $332 \pm 5$ & 2.03 \\
\hline 35 & $346(0.09)$ & 86.5 & 22.1 & 8.12 & 1.141 & 133 & 26.6 & $301 \pm 5$ & 1.79 \\
\hline
\end{tabular}


the vesicle size distribution becomes significantly broader when the $[\text { silica }]_{0}$ is increased from 0 to $35 \% \mathrm{w} / \mathrm{w}$ (see Figure $4 \mathrm{a}$ ). Given that the silica density is $2.06(5) \mathrm{g} \mathrm{cm}^{-3}$ (as judged by helium pycnometry), this suggests that the number of silica nanoparticles encapsulated per vesicle increases at higher $[\text { silica }]_{0}$, as expected. Hence, the effective vesicle density increases, resulting in much faster sedimentation of the vesicles relative to the non-encapsulated silica nanoparticles. This means that DCP analyses can be conducted on the assynthesized dispersions, since the excess silica nanoparticles cannot be detected on the same (short) time scale as the vesicles. However, the vesicle size distribution has finite width, and larger vesicles contain many more silica nanoparticles than smaller vesicles. This leads to a density distribution being superimposed on the vesicle size distribution, which results in its artificial broadening. In principle, this problem can be corrected by calculating the particle density for a given diameter, as reported by Fielding et al. $^{43}$ However, this refinement was not considered necessary in the present work.

SAXS analysis of the $\mathrm{G}_{58} \mathrm{H}_{250}$ diblock copolymer vesicles prepared in the presence of silica nanoparticles indicated volume-average vesicle diameters of $295-335 \mathrm{~nm}$, which are comparable to the mean diameter of $291 \pm 7 \mathrm{~nm}$ obtained for empty vesicles (see Table 1). This suggests that the presence of the silica nanoparticles does not significantly affect the PISA synthesis. Taking the SAXS diameter of the empty vesicles to be the true DCP diameter for both empty and silica-loaded vesicles, the effective vesicle density $\left(\rho_{\text {eff }}\right)$ must vary from 1.071 to $1.141 \mathrm{~g} \mathrm{~cm}^{-3}$ on increasing the $[\text { silica }]_{0}$ from 0 to $35 \% \mathrm{w} / \mathrm{w}$ (see Figure $4 \mathrm{~b}$ ). This difference in $\rho_{\text {eff }}$ allows calculation of (i) the mean number of silica nanoparticles encapsulated per vesicle $\left(N_{\mathrm{sv}}\right)$, (ii) the volume of the vesicle lumen occupied by silica nanoparticles $\left(V_{\mathrm{sl}}\right)$, and (iii) the encapsulation efficiency $\left(E E_{\mathrm{DCP}}\right.$, see eqs $\mathrm{S} 1-\mathrm{S} 8$ in the Supporting Information for calculations). This analysis suggests that $N_{\mathrm{sv}}$ increases from 0 to 133 (see Figure 5a and Table 1), $V_{\mathrm{sl}}$ increases from 0 to $4.76 \%$, and $E E_{\mathrm{DCP}}$ increases from 0 to $27 \%$ on increasing [silica $]_{0}$ from 0 to $35 \% \mathrm{w} / \mathrm{w}$ (see Figure $5 \mathrm{~b}$ and Table 1 ). The $N_{\mathrm{sv}}$ increases monotonically with $[\text { silica }]_{0}$. However, $N_{\mathrm{sv}}$ is lower than the theoretical $N_{s v}$ calculated from geometric considerations. Naively, we expected that the $N_{\mathrm{sv}}$ would be simply comparable to the number of silica nanoparticles that occupy a certain volume for a given $[\text { silica }]_{0}$. However, the silica concentration inside the vesicle lumen is lower than that outside the vesicles. This suggests a mass transport problem: diffusion of the silica nanoparticles within the jellyfish during PISA appears to be relatively slow on the time scale of vesicle formation. Thus, only approximately $27 \%$ of the theoretical maximum amount of silica is actually encapsulated within the vesicle lumen (see Figure $5 b)$.

Thermogravimetric Analysis (TGA). Pyrolysis of the methacrylic copolymer used in this study leaves no incombustible residues on heating up to $800{ }^{\circ} \mathrm{C}$ in air. In contrast, the silica nanoparticles are thermally stable under these conditions. Thus, TGA can be used to determine the encapsulated silica content of dried vesicles after removal of the excess non-encapsulated silica via six centrifugation-redispersion cycles (see TEM images in Figure 2).

The silica nanoparticles used in this work lose $\sim 10.1 \%$ mass on heating to $350{ }^{\circ} \mathrm{C}$ in air during TGA analysis. This is attributed to a combination of surface moisture and also pyrolysis of surface glycerol groups (at $\sim 350{ }^{\circ} \mathrm{C}$ ), which are present for this particular commercial grade. This mass loss

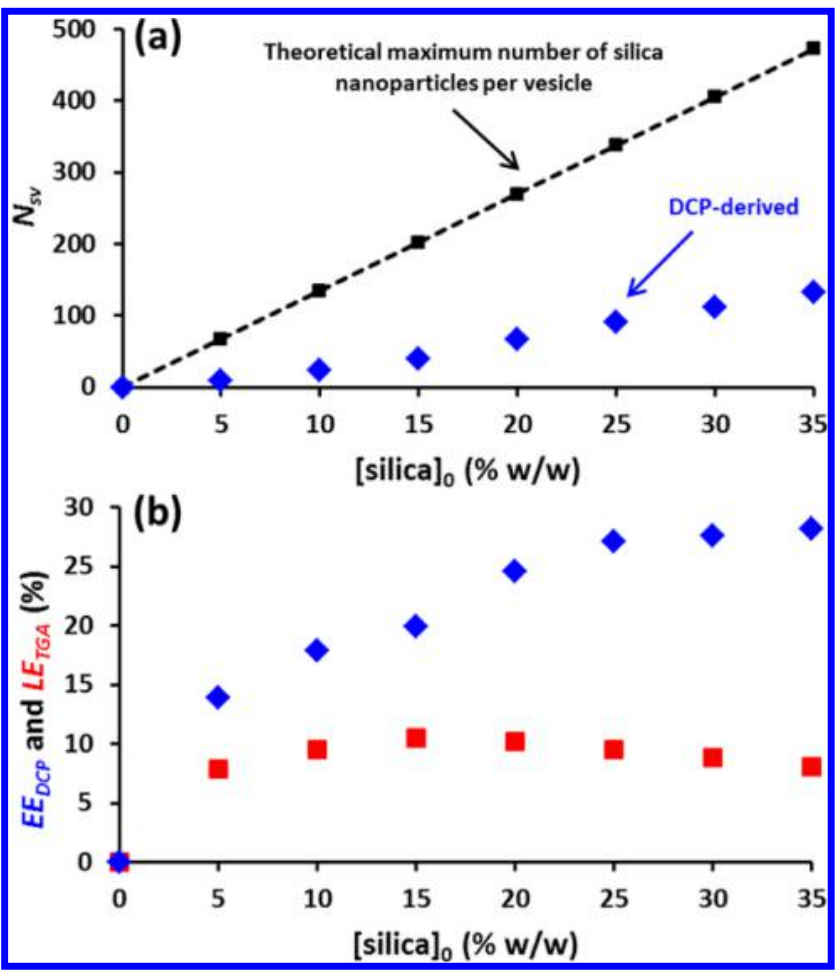

Figure 5. Effect of varying the initial silica concentration, $[\text { silica }]_{0}$, during the in situ loading of silica nanoparticles into $\mathrm{G}_{58} \mathrm{H}_{250}$ diblock copolymer vesicles prepared via RAFT aqueous dispersion polymerization at $70{ }^{\circ} \mathrm{C}$. (a) Comparison of the theoretical maximum number of silica nanoparticles encapsulated per vesicle with that calculated experimentally from DCP data. (b) Comparison of DCP-derived silica encapsulation efficiency $\left(E E_{\mathrm{DCP}}\right)$ and the TGA-derived loading efficiency $\left(L E_{\mathrm{TGA}}\right)$.

must be taken into account when calculating the silica content of the silica-loaded vesicles (see eq S9 in the Supporting Information and also for the data shown in Table 1). As expected, TGA curves recorded prior to centrifugation (see Figure S4a) indicate higher silica contents than those observed after centrifugation (see Figure S4b).

In calculating the TGA-derived loading efficiency $\left(L E_{\mathrm{TGA}}\right.$, see eqs S9 and S10) it is assumed that (i) all the copolymer present has formed vesicles, (ii) there are no empty vesicles, and (iii) all of the excess silica was removed via centrifugation (which is likely to be the case in view of the gravimetric analysis results shown in Figure S5). The $L E_{\mathrm{TGA}}$ remains relatively constant at around $9 \%$ regardless of the $[\text { silica }]_{0}$ (see Figure $5 b$ ). It is perhaps worth emphasizing the difference between $L E_{\mathrm{TGA}}$ and $E E_{\mathrm{DCP}}$. The former parameter is calculated from experimental TGA data and represents the proportion of silica that is encapsulated within the vesicles relative to $[\text { silica }]_{0}$. In contrast, $E E_{D C P}$ is calculated by combining the DCP and SAXS data. SAXS is used to determine an accurate weight-average vesicle diameter, vesicle membrane thickness, and vesicle lumen volume. The numerator term is the mean number of silica nanoparticles per vesicle (determined by using the SAXS diameter to calculate the precise vesicle density required to correct the raw DCP data), while the denominator is calculated by multiplying the $[\text { silica }]_{0}$ by the total vesicle lumen volume divided by the total volume of the solution. This calculation assumes that there are no interactions between the copolymer and the silica. For a given vesicle diameter and $[\text { silica }]_{0}$, the 
denominator term can be used to calculate the theoretical maximum number of silica nanoparticles per vesicle.

Small Angle X-ray Scattering (SAXS). In order to analyze the synchrotron SAXS data obtained for these silica-loaded vesicles, it was necessary to develop an appropriate analytical model. Three types of particles are present in these samples: empty copolymer vesicles (morphology 1), spherical silica nanoparticles (morphology 2), and silica-loaded copolymer vesicles (morphology 3). In general, the silica component scatters X-rays more strongly than the copolymer, but the silica nanoparticles (morphology 2) dominate the scattering intensity at high $q$, whereas the much larger vesicles (morphology 1) dominate the scattering at low $q$. Drawing on our earlier structural characterization of core-shell nanocomposite particles comprising polymer cores and particulate silica shells, ${ }^{44}$ the scattering patterns associated with morphology 3 can be satisfactorily fitted using a two-population model. In this case population 1 corresponds to silica-loaded vesicles and population 2 describes the particulate nature of the corresponding lumen. Thus this two-population model includes a modified version of morphology 1 and morphology 2 and can be applied to all three morphologies. In general, the scattering intensity of a system composed of $n$ different (non-interacting) populations of polydisperse objects can be expressed as:

$$
\begin{aligned}
I(q)= & \sum_{l=1}^{n} S_{l}(q) N_{l} \int_{0}^{\infty} \ldots \int_{0}^{\infty} F_{l}\left(q, r_{l 1}, \ldots, r_{l k}\right) \Psi_{l}\left(r_{l 1}, \ldots, r_{l k}\right) \\
& \mathrm{d} r_{l 1} \ldots \mathrm{d} r_{l k}
\end{aligned}
$$

where $F_{l}\left(q, r_{l 1}, \ldots, r_{l k}\right)$ is the form factor, $\Psi_{l}\left(q, r_{l 1}, \ldots, r_{l k}\right)$ is the distribution function, $N_{l}$ is the number density per unit volume, and $S_{l}(q)$ is the structure factor of the $l$ th population in the system. $r_{l 1}, \ldots, r_{l k}$ is a set of $k$ parameters describing the structural morphology of the $l$ th population. The two-population model can be derived from eq 1 by taking $n=2$ and assigning the silica-loaded copolymer vesicles to population $1(l=1)$ and the spherical silica nanoparticles within the vesicle lumen to population $2(l=2)$. The form factor for population 1 (vesicles) can be described as: ${ }^{45}$

$$
\begin{gathered}
F_{1}(q)=\left[A_{m l}(q)\right]^{2}+N_{\mathrm{agg}} \beta_{\mathrm{c}}^{2} F_{\mathrm{c}}\left(q R_{\mathrm{g}}\right)+N_{\mathrm{agg}}\left(N_{\mathrm{agg}}-1\right) \beta_{\mathrm{c}}^{2} \\
{\left[A_{\mathrm{c}}(q)\right]^{2}+2 N_{\mathrm{agg}} \beta_{\mathrm{c}} A_{m l}(q) A_{\mathrm{c}}(q)}
\end{gathered}
$$

However, this expression requires modification to represent silica-loaded vesicles: the amplitude of the membrane self-term in eq 2 must be replaced by an amplitude representing both the membrane and the silica-loaded lumen expressed as the form factor amplitude for a core-shell spherical particle: ${ }^{46}$

$$
\begin{aligned}
A_{m l}(q)= & \left(1-x_{\mathrm{sol}}\right)\left(\xi_{\mathrm{m}}-\xi_{\mathrm{sol}}\right) V_{\text {out }} \Phi\left(q R_{\mathrm{out}}\right) \\
& +\left[\xi_{l}-\xi_{\mathrm{sol}}-\left(1-x_{\mathrm{sol}}\right)\left(\xi_{\mathrm{m}}-\xi_{\mathrm{sol}}\right)\right] V_{\text {in }} \Phi\left(q R_{\mathrm{in}}\right)
\end{aligned}
$$

where $R_{\mathrm{in}}=R_{\mathrm{m}}-(1 / 2) T_{\mathrm{m}}$ is the radius of the lumen, $R_{\text {out }}=R_{\mathrm{m}}$ $+(1 / 2) T_{\mathrm{m}}$ is the outer radius of the membrane, $V_{\mathrm{in}}=(4 /$ 3) $\pi R_{\text {in }}{ }^{3}$ is the volume of the vesicle lumen, and $V_{\text {out }}=$ (4/ 3) $\pi R_{\text {out }}{ }^{3}$ is the volume of the vesicle. $R_{\mathrm{m}}$ is the radius from the center of the vesicle to the middle of the membrane, $T_{\mathrm{m}}$ is the membrane thickness (Figure 6), and $\Phi(x)=(3[\sin (x)-$ $x \cos (x)]) / x^{3}$ is the form factor amplitude for a homogeneous sphere. The vesicle aggregation number (i.e., the mean number of copolymer chains per vesicle) is given by $N_{\mathrm{agg}}=(1-$ $\left.x_{\text {sol }}\right)\left(V_{\text {out }}-V_{\text {in }}\right) / V_{\mathrm{m}}$, where $x_{\text {sol }}$ is the solvent fraction in the

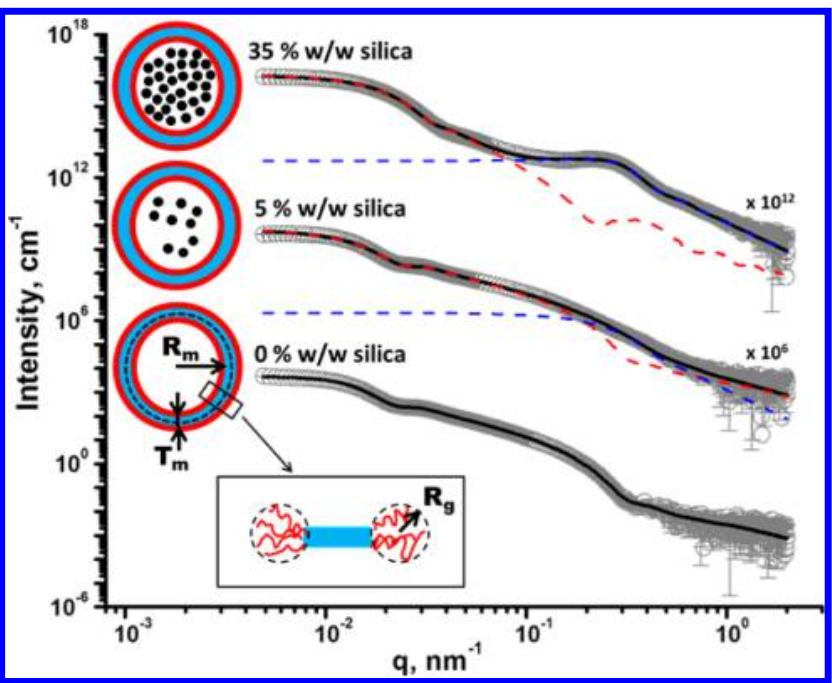

Figure 6. SAXS patterns obtained for $1.0 \% \mathrm{w} / \mathrm{w}$ aqueous dispersions of $\mathrm{G}_{58} \mathrm{H}_{250}$ diblock copolymer vesicles prepared via PISA in the presence of varying amounts of silica nanoparticles $(0 \%, 5 \%$, and $35 \%$ w/w silica). Gray circles represent data, and solid lines represent fitting curves: when no silica was present during the vesicle synthesis, a single-population vesicle model was sufficient to fit the corresponding SAXS pattern, whereas two populations were required when silica nanoparticles were present during the PISA synthesis. Red and blue dashed lines represent populations 1 and 2, respectively. For clarity, the upper two SAXS patterns are shifted vertically by arbitrary scaling factors, as shown on the plot. (Inset) Schematic representation of empty and silica-loaded $\mathrm{G}_{58} \mathrm{H}_{250}$ diblock copolymer vesicles, where small black circles represent silica nanoparticles, red = PGMA block $(\mathrm{G})$, light blue = PHPMA block $(\mathrm{H}), R_{\mathrm{m}}$ is the radius from the center of the vesicle to the middle of the membrane, $T_{\mathrm{m}}$ is the membrane thickness, and $R_{\mathrm{g}}$ is the radius of gyration of the corona.

membrane and $V_{\mathrm{m}}$ is the volume of the membrane-forming hydrophobic PHPMA block $\left(V_{\mathrm{m}}=V_{\text {PHPMA250 }}\right)$. The X-ray scattering length contrast for the corona block is $\beta_{\mathrm{c}}=V_{\mathrm{c}}\left(\xi_{\mathrm{c}}-\right.$ $\left.\xi_{\text {sol }}\right)$, where $V_{\mathrm{c}}$ is the corona block volume $\left(V_{\mathrm{PGMA58}}\right)$. The block volumes are calculated from $V=M_{\mathrm{w}} /\left(\rho N_{\mathrm{A}}\right)$ using the weight-average molecular weight, $M_{\mathrm{w}}$, of the block components and the mass densities of the three blocks comprising the copolymer $\left(\rho_{\text {PHPMA }}=1.21 \pm 0.01 \mathrm{~g} \mathrm{~cm}^{-3}\right.$ and $\rho_{\mathrm{PGMA}}=1.31 \pm$ $0.01 \mathrm{~g} \mathrm{~cm}^{-3}$; these values were determined for the corresponding homopolymers using helium pycnometry). $\xi_{\text {sol }}$, $\xi_{\mathrm{m}}, \xi_{\mathrm{c}}$ and $\xi_{1}$ are the X-ray scattering length densities of the surrounding solvent $\left(\xi_{\mathrm{H}_{2} \mathrm{O}}=9.42 \times 10^{10} \mathrm{~cm}^{-2}\right)$, the membraneforming hydrophobic block $\left(\xi_{\text {PHPMA }}=11.11 \times 10^{10} \mathrm{~cm}^{-2}\right)$, the vesicle corona block $\left(\xi_{\text {PGMA }}=11.94 \times 10^{10} \mathrm{~cm}^{-2}\right)$, and the vesicle lumen $\left[\xi_{l}=\left(1-V_{\mathrm{SiO}_{2}} / V_{\mathrm{in}}\right) \xi_{\mathrm{H}_{2} \mathrm{O}}+\left(V_{\mathrm{SiO}_{2}} / V_{\mathrm{in}}\right) \xi_{\mathrm{SiO}_{2}}\right.$ where $\xi_{\mathrm{SiO}_{2}}=17.5 \times 10^{10} \mathrm{~cm}^{-2}$ and $V_{\mathrm{SiO}_{2}}$ is the volume occupied by silica nanoparticles within the lumen]. It should be mentioned that the X-ray scattering length contrast for the membrane block is given by $\beta_{\mathrm{m}}=V_{\mathrm{m}}\left(\xi_{\mathrm{m}}-\xi_{\mathrm{sol}}\right)$. Thus the $\left(\beta_{\mathrm{c}} /\right.$ $\left.\beta_{\mathrm{m}}\right)^{2}$ ratio is approximately 0.08 , which suggests that the profile of the electron density distribution within the corona should be included in the model. However, recent modeling of experimental data on a similar system has demonstrated that incorporation of a profile function in the model has a negligible effect on the derived structural parameters. ${ }^{38}$ The selfcorrelation term for the corona block in eq 2 is given by the Debye function, $F_{\mathrm{c}}\left(q R_{\mathrm{g}}\right)=\left(2\left[\exp \left(-q^{2} R_{\mathrm{g}}^{2}\right)-1+q^{2} R_{\mathrm{g}}^{2}\right]\right) /\left(q^{4} R_{\mathrm{g}}^{4}\right)$, where $R_{\mathrm{g}}$ is the radius of gyration of the corona block (Figure 
6). Assuming that there is no penetration of the corona blocks within the membrane, the amplitude of the corona self-term is expressed as:

$$
\begin{aligned}
A_{\mathrm{c}}(q)= & \Psi\left(q R_{\mathrm{g}}\right) \frac{1}{2}\left[\frac{\sin \left[q\left(R_{\text {out }}+R_{\mathrm{g}}\right)\right]}{q\left(R_{\text {out }}+R_{\mathrm{g}}\right)}\right. \\
& \left.+\frac{\sin \left[q\left(R_{\text {in }}-R_{\mathrm{g}}\right]\right.}{q\left(R_{\text {in }}-R_{\mathrm{g}}\right)}\right]
\end{aligned}
$$

where $\Psi\left(q R_{\mathrm{g}}\right)=\left(1-\exp \left(-q R_{\mathrm{g}}\right)\right) /\left(q R_{\mathrm{g}}\right)^{2}$ is the form factor amplitude of the corona chain. The polydispersities for two parameters $\left(R_{\mathrm{m}}\right.$ and $\left.T_{\mathrm{m}}\right)$, expressed as a Gaussian distribution, are considered for the first (silica-loaded vesicle) population:

$$
\begin{aligned}
\Psi_{1}\left(r_{11}, r_{12}\right)= & \frac{1}{\sqrt{2 \pi \sigma_{R \mathrm{~m}}^{2}}} e^{-\left(r_{11}-R_{\mathrm{m}}\right)^{2} / 2 \sigma_{R \mathrm{~m}}^{2}} \frac{1}{\sqrt{2 \pi \sigma_{T \mathrm{~m}}^{2}}} \\
& e^{-\left(r_{12}-T_{\mathrm{m}}\right)^{2} / 2 \sigma_{T \mathrm{~m}}^{2}}
\end{aligned}
$$

where $\sigma_{R \mathrm{~m}}$ and $\sigma_{T \mathrm{~m}}$ are the standard deviations for $R_{\mathrm{m}}$ and $T_{\mathrm{m}}$, respectively. The number density per unit volume of population $1(l=1$ in eq 1$)$ is expressed as:

$$
N_{1}=\frac{c_{1}}{\int_{0}^{\infty} \int_{0}^{\infty} V_{1}\left(r_{11}, r_{12}\right) \Psi_{1}\left(r_{11}, r_{12}\right) \mathrm{d} r_{11} \mathrm{~d} r_{12}}
$$

where $c_{1}$ is the total volume fraction of copolymer molecules forming vesicles in the sample and $V_{1}\left(r_{11}, r_{12}\right)$ is the total volume of copolymers in a vesicle $\left[V_{1}\left(r_{11}, r_{12}\right)=\left(V_{\mathrm{m}}+V_{\mathrm{c}}\right)\right.$ $\left.N_{\mathrm{agg}}\left(r_{11}, r_{12}\right)\right]$. It is assumed that the vesicle dispersion is sufficiently dilute to enable the structure factor for population 1 to be set to unity $\left[S_{1}(q)=1\right]$. Population 1 describes scattering from a vesicle with a homogeneous lumen. However, the lumen actually has a particulate structure arising from the encapsulated silica nanoparticles. This generates an additional scattering signal that can be described by population 2 , for which $l=2$ in eq 1 . The form factor for this population is simply that for a homogeneous sphere:

$$
F_{2}(q)=\left(\xi_{\mathrm{SiO}_{2}}-\xi_{\mathrm{sol}}\right)^{2} \Phi^{2}\left(q R_{\mathrm{SiO}_{2}}\right)
$$

where $R_{\mathrm{SiO}_{2}}$ is the mean radius of the silica nanoparticles. All other parameters and functions in the model for population 2 are analogous to those for population 1 (eq 2). The polydispersity of one parameter $\left(R_{\mathrm{SiO}_{2}}\right)$, expressed as a Gaussian distribution, is considered for population 2 :

$$
\Psi_{2}\left(r_{2 l}\right)=\frac{1}{\sqrt{2 \pi \sigma_{R_{\mathrm{SiO}_{2}}}^{2}}} e^{-\left(r_{21}-R_{\mathrm{SiO}_{2}}\right)^{2} / 2 \sigma_{\mathrm{SiO}_{2}}^{2}}
$$

where $\sigma_{R_{\mathrm{S} \text { iO2 }}}$ is the standard deviation for $R_{\mathrm{SiO}_{2}}$. The number density per unit volume of population 2 is expressed as:

$$
N_{2}=\frac{c_{2}}{\int_{0}^{\infty} V_{2}\left(r_{21}\right) \Psi_{2}\left(r_{21}\right) \mathrm{d} r_{21}}
$$

where $c_{2}$ is the total volume fraction of silica particles in the sample and $V_{2}\left(r_{21}\right)=(4 / 3) \pi r_{21}^{3}$ is the volume of a single spherical silica nanoparticle. Since interparticle interactions are expected for silica particles occupying the vesicle lumen, a hardsphere interaction structure factor based on the Percus-Yevick approximation ${ }^{47}$ was introduced into the model for population 2:

$$
S_{2}(q)=S_{\mathrm{PY}}\left(q, R_{\mathrm{PY}}, f_{\mathrm{PY}}\right)
$$

where $R_{\mathrm{PY}}$ is the interaction radius and $f_{\mathrm{PY}}$ is an effective hardsphere volume fraction. The model was incorporated in Irena SAS macros for Igor Pro software, ${ }^{48}$ and numerical integration of eqs 1,6 , and 9 was used for data fitting.

Accordingly, use of population 1 alone was sufficient for satisfactory data fits to SAXS patterns obtained for empty $\mathrm{G}_{58} \mathrm{H}_{250}$ diblock copolymer vesicles synthesized in the absence of any silica nanoparticles. Use of the vesicle model $(l=1$ in eq 1 and $\xi_{l}=\xi_{\text {sol }}$ in eq 3) produced a reasonably good fit over 7 orders of magnitude of X-ray scattering intensity (see Figure 6). The overall vesicle radius, $R_{\mathrm{v}}=R_{\text {out }}+2 R_{g}$, was calculated to be $145.5 \mathrm{~nm}$ (Table S1), which is consistent with both TEM observations (Figure 2) and DLS data (Table 1). The $R_{g}$ of the $\mathrm{G}_{58}$ corona block was determined to be $2.3 \mathrm{~nm}$ from fitting of the $\mathrm{G}_{58} \mathrm{H}_{250}$ SAXS pattern. ${ }^{38}$ This experimental value is comparable to a theoretical estimate: the projected contour length of a single GMA monomer is $0.255 \mathrm{~nm}$ (two carbon bonds in all-trans conformation), the total contour length of a $\mathrm{G}_{58}$ block, $L_{\mathrm{PGMA}}=58 \times 0.255 \mathrm{~nm}=14.79 \mathrm{~nm}$, and the Kuhn length of $1.53 \mathrm{~nm}$, based on the literature value for poly(methyl methacrylate), ${ }^{49}$ result in an estimated $R_{g}$ of $(14.79 \times 1.53 /$ $6)^{1 / 2}$ or $1.94 \mathrm{~nm}$. The SAXS data fit suggested that the hydrophobic PHPMA component of the vesicle membrane was solvated, $x_{\text {sol }}=0.16$.

In order to produce satisfactory fits to SAXS patterns obtained for $\mathrm{G}_{58} \mathrm{H}_{250}$ diblock copolymer vesicles prepared in the presence of silica nanoparticles, incorporation of population $2(l=2$ in eq 1$)$ into the model was essential. It was also assumed for the fitting that all silica nanoparticles represented by population 2 are located within the vesicles. Thus the volume fraction of silica nanoparticles, $c_{2}$, and the scattering length density of the lumen, $\xi_{\text {l }}$, must be related in order to produce a self-consistent model. In this respect, the scattering length density of the lumen can be expressed as $\xi_{l}=\left(1-c_{2} /\right.$ $\left.c_{l}\right) \xi_{\mathrm{H}_{2} \mathrm{O}}+\left(c_{2} / c_{l}\right) \xi_{\mathrm{SiO}_{2}}$, where $c_{l}=\left(c_{1} V_{\text {in }}\right) /\left(\left(V_{\text {out }}-V_{\text {in }}\right)\left(1-x_{\text {sol }}\right)\right)$, is the total volume fraction of the vesicle lumen.

Structural parameters for the silica nanoparticles alone were obtained from SAXS patterns recorded for $0.1 \%, 1 \%$, and $5 \%$ w/w aqueous silica sols (see Figure S6). In this case, only population 2 of the model was required for satisfactory data fits. The silica nanoparticle radius $\left(R_{\mathrm{SiO}_{2}}\right)$ was estimated to be $9.2 \pm$ $2.1 \mathrm{~nm}$ in all cases. Fittings for the $1 \%$ and $5 \% \mathrm{w} / \mathrm{w}$ silica SAXS patterns required a hard-sphere interaction structure factor (see eq 10 ), because a pronounced peak at $q \approx 0.25 \mathrm{~nm}^{-1}$ was observed at higher silica concentrations. In contrast, no structure factor was observed for the $0.1 \% \mathrm{w} / \mathrm{w}$ silica sol, as expected.

A superposition of X-ray scattering signals from the two populations used in the model produced good fits to the SAXS data obtained for vesicles synthesized in the presence of silica nanoparticles after removal of excess non-encapsulated silica (Figure 6 and Table S1). It is assumed that both the $R_{\mathrm{g}}$ of the PGMA block and the water content within the vesicle membrane are independent of $[\text { silica }]_{0}$. This is reasonable because the same batch of PGMA macro-CTA was utilized and the same PHPMA block degree of polymerization (DP) was targeted in all cases. Thus the $R_{\mathrm{g}}$ and $x_{\text {sol }}$ values obtained for $\mathrm{G}_{58} \mathrm{H}_{250}$ diblock copolymer vesicles synthesized in the absence of any silica were also used for SAXS fitting of the vesicles synthesized in the presence of silica nanoparticles. Moreover, 


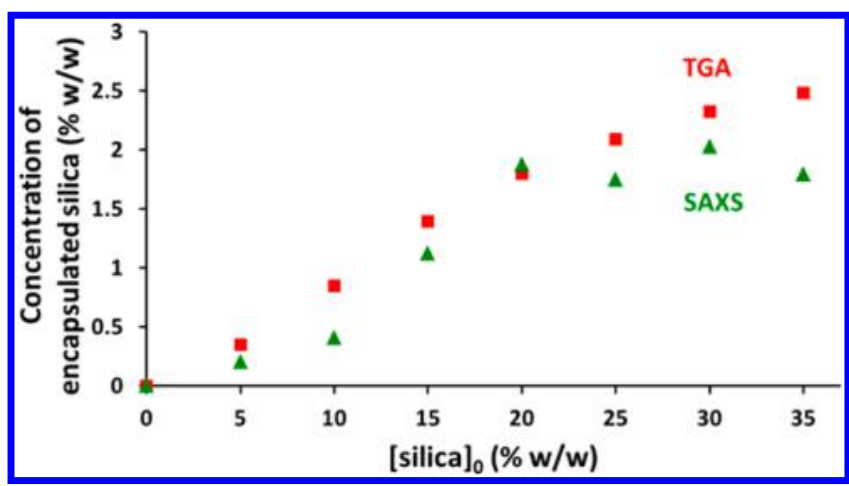

Figure 7. Effect of varying the initial silica concentration, $[\text { silica }]_{0}$, on the concentration of encapsulated silica, as calculated using SAXS (green triangles, measured at $1.0 \% \mathrm{w} / \mathrm{w}$ copolymer) and TGA (red circles) for $\mathrm{G}_{58} \mathrm{H}_{250}$ diblock copolymer vesicles prepared at $10 \% \mathrm{w} / \mathrm{w}$ in the presence of $0-35 \% \mathrm{w} / \mathrm{w}$ silica nanoparticles (after six centrifugation-redispersion cycles).

SAXS analysis shows that both $T_{\mathrm{m}}$ and $R_{\mathrm{v}}$ remain virtually constant regardless of $[\text { silica }]_{0}\left(T_{\mathrm{m}} \approx 15.9 \mathrm{~nm}\right.$ and $R_{\mathrm{v}} \approx 145.5$ $\mathrm{nm}$, Table S1), which is consistent with our TEM observations (Figure 2) and DLS data (Table 1). This confirms that the dimensions of the empty vesicles produced using this PISA formulation in the absence of any silica are comparable to those obtained in the presence of the silica nanoparticles (see Table $1)$. It is emphasized that the broad peak at $q \approx 0.25 \mathrm{~nm}^{-1}$, which is associated with interacting silica nanoparticles, confirms successful silica encapsulation within the vesicles. Moreover, increasing the $[\text { silica }]_{0}$ leads to both a higher effective volume fraction and a reduction in the correlation distance between silica nanoparticles $\left(f_{\mathrm{PY}}\right.$ and $R_{\mathrm{PY}}$, respectively, see Table S1), which suggests a greater packing density for the silica nanoparticles within the vesicle lumen. This was corroborated by control experiments in which silica nanoparticles were added to empty vesicles to afford dispersions of the same overall silica concentration. SAXS patterns recorded for such dispersions did not possess any peak at $q \approx 0.25 \mathrm{~nm}^{-1}$ corresponding to silica nanoparticles, indicating that no structure factor is required in this case (see Figure S7). These SAXS observations confirm beyond any reasonable doubt that the silica nanoparticles are indeed encapsulated within the vesicles during these PISA syntheses.

The concentration of encapsulated silica nanoparticles (see Table 1) can be estimated using the volume fraction of silica nanoparticles $\left(c_{2}\right)$ obtained from the fitted SAXS patterns. In general, the SAXS data are in fairly good agreement with the corresponding TGA data (see Figure 7). However, SAXS tends to underestimate the concentration of encapsulated silica at higher $[\text { silica }]_{0}$. In principle, this might be because TGA cannot distinguish between the silica nanoparticles located within the vesicles and any excess, non-encapsulated silica that might remain in the aqueous continuous phase. In contrast, the twopopulation SAXS model used in this work is mainly sensitive to silica nanoparticles located within the vesicle lumen. However, TEM studies coupled with gravimetric analysis of successive supernatants suggest that there is relatively little, if any, nonencapsulated silica present after six centrifugation-redispersion cycles (see Figures 2 and S5, respectively). This discrepancy arises because DCP reports artificially broadened, highly asymmetric size distributions at higher $[\text { silica }]_{0}$, as discussed earlier. This is essentially a polydispersity effect: heavier vesicles containing relatively high silica loadings appear larger in the
DCP size distribution, whereas lighter vesicles containing fewer encapsulated silica nanoparticles appear smaller, giving rise to an artificially skewed distribution.

This polydispersity effect also leads to uncertainty in the calculated copolymer volume fraction $\left(c_{1}\right)$. The copolymer concentration was actually kept constant at $1.0 \% \mathrm{w} / \mathrm{w}$ for all SAXS measurements. However, the SAXS model incorrectly suggests that the copolymer concentration is reduced 10 -fold as the $[\text { silica }]_{0}$ is increased from 0 to $35 \% \mathrm{w} / \mathrm{w}$. Such a significant discrepancy must be associated with the broad distribution of $N_{\text {sv }}$ indicated by DCP measurements. The latter technique shows that at low $[\text { silica }]_{0}$ there is a relatively symmetric (approximately Gaussian) distribution of silica nanoparticles per vesicle. However, vesicle dispersions prepared at higher [silica $]_{0}$ exhibit significantly broader, highly asymmetric distributions skewed to higher mass (Figure 4). This effect is enhanced because $\xi_{\mathrm{SiO}_{2}}$ is higher than that of the copolymer $\left(17.5 \times 10^{10}\right.$ vs $11.11 \times 10^{10} \mathrm{~cm}^{-2}$, respectively), so heavily loaded vesicles scatter much more strongly than lightly loaded (or empty) vesicles. This bias becomes important at higher $[\text { silica }]_{0}$, resulting in a lower apparent copolymer concentration. In contrast, for $[\text { silica }]_{0}=5 \% \mathrm{w} / \mathrm{w}$, the particle size distribution is relatively narrow and symmetric (approximately Gaussian), meaning that the SAXS data are more reliable in this regime. For PISA syntheses conducted at this relatively low $[\text { silica }]_{0}$, the mean number of silica nanoparticles per vesicle is calculated to be 9 and 14 for DCP and SAXS, respectively.

In principle, the problem in the SAXS analysis observed at high $[\text { silica }]_{0}$ could be rectified by incorporating an additional function in order to account for the polydispersity of $N_{\mathrm{sv}}$. However, the current SAXS model already incorporates three polydispersity functions (eqs 5 and 8): an extra function describing the asymmetric distribution of $N_{\mathrm{sv}}$ would significantly complicate the data analysis and is beyond the scope of this work.

Thermally Triggered Release of Silica Nanoparticles. In the light of recent work by Leibler and co-workers, the controlled release of silica nanoparticles from vesicles could offer a self-repair mechanism for either synthetic hydrogels or living tissues. ${ }^{40}$ For the $\mathrm{G}_{58} \mathrm{H}_{250}$ diblock copolymer vesicles described herein, a relatively low degree of polymerization (DP) was targeted for the thermoresponsive PHPMA block because we wished to explore the feasibility of controlled release of the encapsulated silica nanoparticles.

In control experiments performed in the absence of any silica nanoparticles, TEM studies confirmed that the $\mathrm{G}_{58} \mathrm{H}_{250}$ diblock copolymer vesicles underwent a morphology change to produce a mixture of diblock copolymer spheres and short worm-like micelles on cooling to $0{ }^{\circ} \mathrm{C}$ for $30 \mathrm{~min}$ (see Figure S8).

For silica-loaded $\mathrm{G}_{58} \mathrm{H}_{250}$ diblock copolymer vesicles prepared in the presence of $5 \% \mathrm{w} / \mathrm{w}$ silica nanoparticles, a similar change in morphology was observed on cooling (see Figure 8a). Such vesicle dissociation leads to release of the encapsulated silica nanoparticles, which results in loss of the silica structure factor in the corresponding SAXS pattern. Thus, this thermally triggered transition confirms that the silica nanoparticles are indeed encapsulated within the vesicle lumen.

SAXS was utilized to explore the kinetics of silica nanoparticle release at $0{ }^{\circ} \mathrm{C}$ (see Figure 9). Time-resolved SAXS studies indicated that intact silica-loaded vesicles were still present after $6 \mathrm{~min}$ at $0{ }^{\circ} \mathrm{C}$. Close inspection of these SAXS patterns confirmed that the local minimum at $q \approx 0.02 \mathrm{~nm}^{-1}$, 


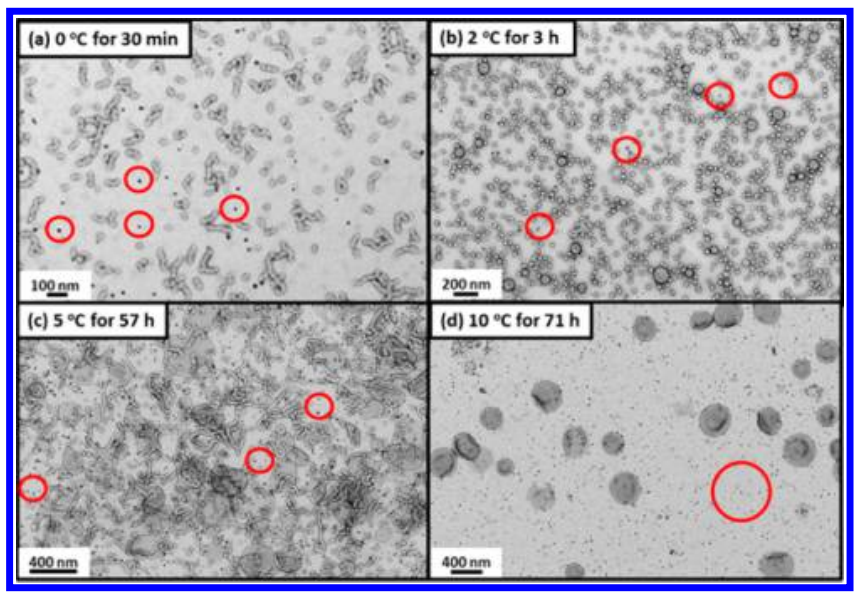

Figure 8. TEM images obtained for $\mathrm{G}_{58} \mathrm{H}_{250}$ diblock copolymer vesicles synthesized in the presence of $5 \% \mathrm{w} / \mathrm{w}$ silica nanoparticles (see Figure 2) after cooling to (a) $0{ }^{\circ} \mathrm{C}$ for $30 \mathrm{~min}$, (b) $2{ }^{\circ} \mathrm{C}$ for $3 \mathrm{~h}$, (c) $5{ }^{\circ} \mathrm{C}$ for $57 \mathrm{~h}$, and (d) $10{ }^{\circ} \mathrm{C}$ for $71 \mathrm{~h}$. Cooling results in the release of the encapsulated silica nanoparticles, which are more electron-dense than the copolymer nanoparticles (red circles depict free silica nanoparticles). Cooling to 0 or $2{ }^{\circ} \mathrm{C}$ causes vesicles to dissociate to spherical micelles and short worm-like micelles, cooling to $5{ }^{\circ} \mathrm{C}$ results in jellyfish, worms, and lamellae, and cooling to only 10 ${ }^{\circ} \mathrm{C}$ results in minimal vesicle disintegration.

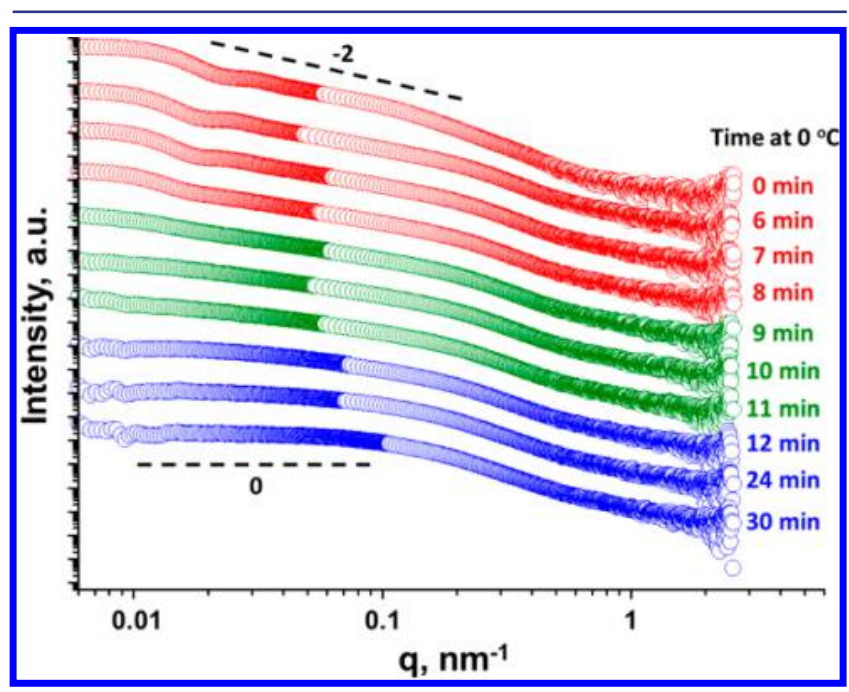

Figure 9. SAXS patterns obtained for $1.0 \% \mathrm{w} / \mathrm{w}$ aqueous dispersions of $\mathrm{G}_{58} \mathrm{H}_{250}$ diblock copolymer vesicles (originally prepared via PISA at $10 \% \mathrm{w} / \mathrm{w}$ copolymer in the presence of $5 \% \mathrm{w} / \mathrm{w}$ silica). The excess/ non-encapsulated silica nanoparticles were removed via six centrifugation-redispersion cycles. Then the purified silica-loaded $\mathrm{G}_{58} \mathrm{H}_{250}$ vesicles were cooled to $0{ }^{\circ} \mathrm{C}$ for $30 \mathrm{~min}$ while scattering patterns were collected every $15 \mathrm{~s}$. Selected SAXS patterns recorded after various times at $0{ }^{\circ} \mathrm{C}$ are shown (for clarity, these patterns are shifted vertically by an arbitrary scaling factor). Silica-loaded vesicles are present up to 8 min (red circles) but undergo dissociation to form worm-like micelles after $9 \mathrm{~min}$ (green circles), followed by further transformation to produce mainly spheres after $12 \mathrm{~min}$ (blue circles).

which is associated with the vesicle form factor, disappeared after $9 \mathrm{~min}$ at $0{ }^{\circ} \mathrm{C}$. Moreover, the gradient of the scattering pattern at low $q$ is reduced from -2 to -1 after 9 min, indicating the formation of worm-like micelles. This gradient tends to zero after $12 \mathrm{~min}$ at $0{ }^{\circ} \mathrm{C}$, suggesting further vesicle dissociation to form a mixture of spheres and short worm-like micelles. Furthermore, the final pattern after $30 \mathrm{~min}$ at $0{ }^{\circ} \mathrm{C}$ is identical to that obtained after $12 \mathrm{~min}$, confirming that the morphological transition is essentially complete after $12 \mathrm{~min}$. Further time-resolved SAXS studies were conducted for silicaloaded vesicles prepared in the presence of $10-35 \% \mathrm{w} / \mathrm{w}$ silica nanoparticles, which will be reported elsewhere in due course.

Leibler's recent pioneering study ${ }^{40}$ suggests that silica nanoparticles can be utilized as remarkably effective adhesives for the repair of both synthetic hydrogels and biological tissue. More specifically, two cut pieces of either polydimethylacrylamide gel or calf's liver can be glued together simply by spreading an aqueous solution of $30 \mathrm{~nm}$ commercial silica nanoparticles on the two freshly cleaved interfaces and applying light pressure for $30 \mathrm{~s}$. In the context of the present study, we hypothesize that silica nanoparticles encapsulated within vesicles are not available for the repair of either synthetic hydrogels or biological tissue. However, after their thermally triggered release from the vesicles, the silica nanoparticles should be able to act as an effective adhesive. However, for a useful self-healing system it may be preferable to achieve silica nanoparticle release at higher temperatures than $0{ }^{\circ} \mathrm{C}$. Temperature-dependent DLS studies (see Figure S9a) indicate the onset of vesicle dissociation at around $10{ }^{\circ} \mathrm{C}$, as judged by the reduction in count rate and mean particle diameter $\left(D_{\mathrm{h}}\right)$. Time-resolved DLS studies show that the rate of dissociation is significantly faster at lower temperature. For example, $D_{\mathrm{h}}$ decreases from approximately $350 \mathrm{~nm}$ to $76 \mathrm{~nm}$ after $2 \mathrm{~h}$ at $2{ }^{\circ} \mathrm{C}$, with a concomitant reduction in count rate from 22000 to $1000 \mathrm{kcps}$ (see Figure S9b). TEM images verify release of the encapsulated silica nanoparticles, plus the coexistence of copolymer spheres (see Figure $8 \mathrm{~b}$ ). After aging at $5{ }^{\circ} \mathrm{C}$ for $57 \mathrm{~h}$, $D_{\mathrm{h}}$ increases to $523 \mathrm{~nm}$ before decreasing to $284 \mathrm{~nm}$, which suggests vesicle swelling prior to their dissociation (see Figure S9c). However, the final $D_{\mathrm{h}}$ value is not consistent with sphere formation. This is confirmed by TEM, which reveals the formation of a complex mixture of lamellae and worm-like micelles under these conditions (see Figure 8c). Nevertheless, the encapsulated silica nanoparticles are still released (see red circles in Figure 8c). Moreover, aging for $71 \mathrm{~h}$ at $10{ }^{\circ} \mathrm{C}$, both $D_{\mathrm{h}}$ and the count rate remain constant at around $350 \mathrm{~nm}$ and $20000 \mathrm{kcps}$, respectively, which at first sight suggests that the silica-loaded vesicles are not thermoresponsive under these conditions (see Figure S9d). Indeed, TEM images reveal that some vesicles are still intact, yet at least some originally encapsulated silica nanoparticles were released, indicating that a minor fraction of vesicles undergo dissociation (see Figure $8 \mathrm{~d}$ ). In summary, both the extent and the rate of release of encapsulated silica nanoparticles can be fine-tuned by varying the release temperature and aging time. In principle, it would be desirable to conduct time-resolved SAXS studies of the silicaloaded vesicles at 2,5 , or $10{ }^{\circ} \mathrm{C}$, but the much longer experimental time scales required (days) preclude such experiments.

Protein Encapsulation. We wished to examine whether the above findings with silica nanoparticles could be extended to include a model globular protein (bovine serum albumin, BSA). Thus, we conducted RAFT aqueous dispersion polymerization of HPMA at $37{ }^{\circ} \mathrm{C}$ using a low-temperature initiator (VA-044) to obtain $\mathrm{G}_{55} \mathrm{H}_{270}$ diblock copolymer vesicles. These relatively mild conditions were essential in order to avoid denaturation of the protein cargo. The rate of HPMA polymerization was significantly slower at $37{ }^{\circ} \mathrm{C}$, but nevertheless essentially full conversion $(>99 \%)$ was achieved within 8 $\mathrm{h}$ as judged by ${ }^{1} \mathrm{H}$ NMR studies (see Figure S10a). GPC studies 
confirmed that a near-monodisperse diblock copolymer was obtained with minimal macro-CTA contamination and a high blocking efficiency $\left(M_{\mathrm{w}} / M_{\mathrm{n}}=1.16\right.$; see Figure S10b). TEM images (see Figure 10a) reveal a pure vesicular morphology, as expected when targeting such an asymmetric $\mathrm{G}_{55} \mathrm{H}_{270}$ diblock copolymer composition. The vesicles are not affected by this

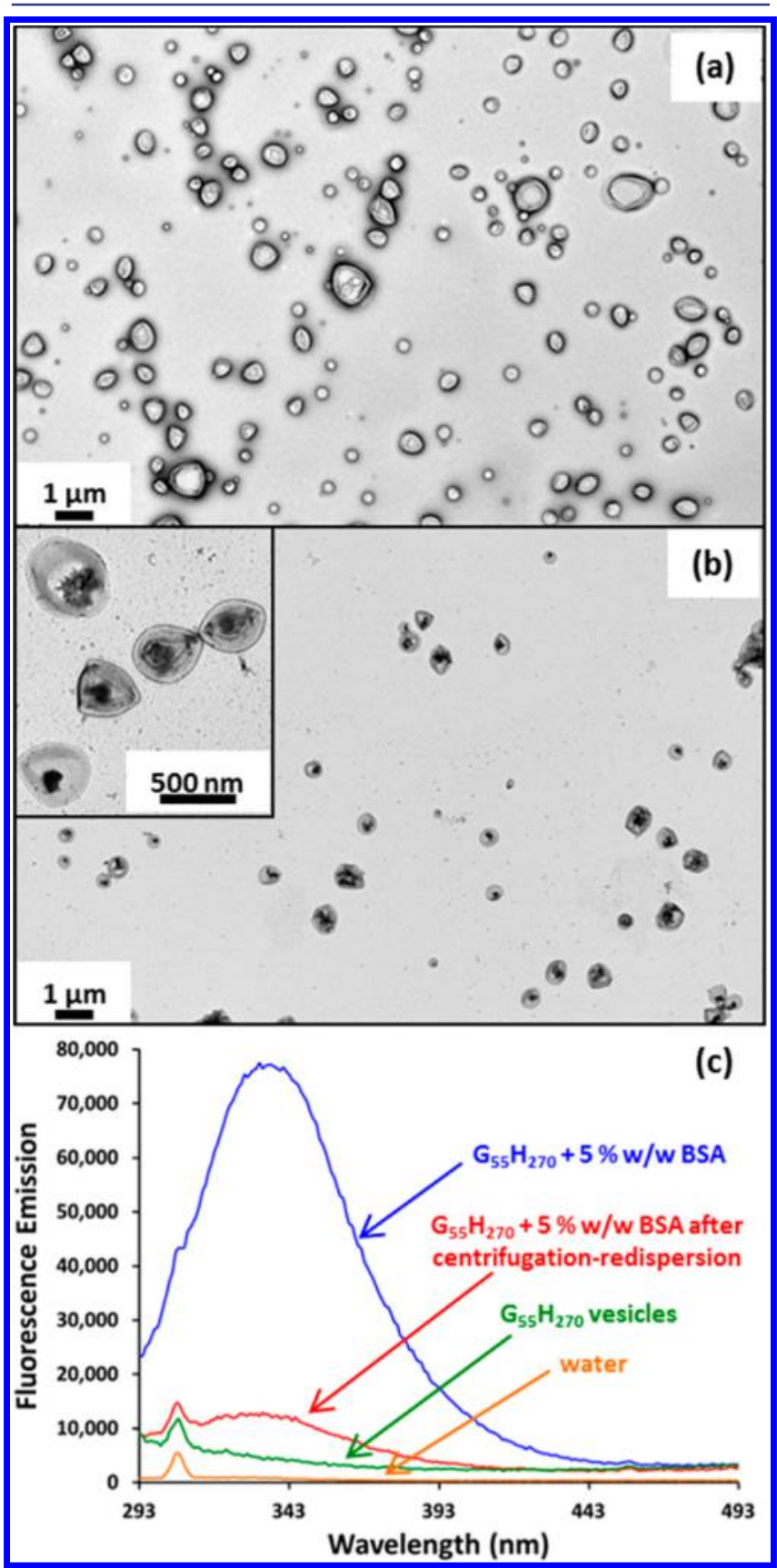

Figure 10. TEM images obtained for $\mathrm{G}_{55} \mathrm{H}_{270}$ diblock copolymer vesicles prepared via PISA at $10 \% \mathrm{w} / \mathrm{w}$ copolymer at $37{ }^{\circ} \mathrm{C}$ in the (a) absence of BSA and (b) presence of $5 \% \mathrm{w} / \mathrm{w}$ BSA (after six centrifugation-redispersion cycles to remove non-encapsulated BSA). (c) In order to calculate the BSA loading efficiency within the vesicles, fluorescence emission spectra were recorded for both the empty $\mathrm{G}_{55} \mathrm{H}_{270}$ vesicles and the BSA-loaded $\mathrm{G}_{55} \mathrm{H}_{270}$ vesicles before and after centrifugation. The background fluorescence emission spectrum of water was also recorded (the sharp signal at $305 \mathrm{~nm}$ is a Raman water band). [N.B. BSA exhibits weak intrinsic fluorescence; absorption at $278 \mathrm{~nm}$ and emission at $337 \mathrm{~nm}]$. $^{50,51}$ low-temperature PISA formulation, suggesting that it may be possible to encapsulate proteins or other delicate biomolecules (e.g., DNA, RNA, antibodies, enzymes etc.) intact under mild conditions. To examine this hypothesis, $\mathrm{G}_{55} \mathrm{H}_{270}$ diblock copolymer vesicles were synthesized at $37{ }^{\circ} \mathrm{C}$ in the presence of $5 \% \mathrm{w} / \mathrm{w}$ BSA. GPC studies indicated that near-monodisperse diblock copolymers were obtained with a comparable $M_{n}$, minimal macro-CTA contamination, and high blocking efficiencies $\left(M_{\mathrm{w}} / M_{\mathrm{n}}=1.17\right.$; see Figure $\left.S 10 \mathrm{~b}\right)$, despite the presence of BSA. After removal of the non-encapsulated BSA via six centrifugation-redispersion cycles, TEM images confirmed the expected vesicular morphology (see Figure $10 \mathrm{~b})$. Moreover, encapsulated BSA is discernible within the vesicle lumen. It should be noted that BSA is a monothiolfunctional protein, which in principle can participate in radicalbased polymerizations. ${ }^{52-54}$ However, GPC, TEM, and ${ }^{1} \mathrm{H}$ NMR studies suggest that this $37{ }^{\circ} \mathrm{C}$ PISA formulation is not adversely affected by the presence of $5 \% \mathrm{w} / \mathrm{w}$ BSA.

Conveniently, BSA is intrinsically fluorescent: it absorbs at $278 \mathrm{~nm}$ and emits at $337 \mathrm{~nm},{ }^{50,51}$ which enables the loading efficiency of BSA within the vesicles $\left(L E_{\mathrm{BSA}}\right)$ to be calculated. First, the fluorescence emission was obtained for a series of aqueous BSA dispersions, with concentrations ranging from $0.00075 \%$ to $0.01 \% \mathrm{w} / \mathrm{w}$ (see Figure S11a). From these data, a linear calibration plot was constructed (see Figure S11b). Fluorescence spectra were obtained for (i) $\mathrm{G}_{55} \mathrm{H}_{270}$ vesicles synthesized in the presence of $5 \% \mathrm{w} / \mathrm{w}$ BSA, (ii) $\mathrm{G}_{55} \mathrm{H}_{270}$ vesicles synthesized in the presence of $5 \% \mathrm{w} / \mathrm{w}$ BSA after purification by centrifugation-redispersion, and (iii) for $\mathrm{G}_{55} \mathrm{H}_{270}$ vesicles synthesized in the absence of BSA (see Figure 10c). The emission at $337 \mathrm{~nm}$ for the latter dispersion was subtracted from that of the former dispersions in order to normalize the data. Using this calibration plot, $[\mathrm{BSA}]_{0}$ was calculated to be $5.19 \% \mathrm{w} / \mathrm{w}$, whereas the concentration of encapsulated BSA, $[\mathrm{BSA}]_{\mathrm{e}}$, was determined to be $0.559 \% \mathrm{w} / \mathrm{w}$, indicating a $L E_{\mathrm{BSA}}$ of $10.8 \%$ (see eqs $S 11-13$ ). This calculation assumes that all of the non-encapsulated BSA was removed via six centrifugation-redispersion cycles. Analysis of successive supernatants after each centrifugation cycle indicates that most $(3.6 \% \mathrm{w} / \mathrm{w})$ of the non-encapsulated BSA was removed during the first centrifugation-redispersion cycle, and the amount of non-encapsulated BSA remaining in the supernatant after six centrifugation-redispersion cycles is negligible (see Figure S12).

During the preparation of this manuscript, Zhang et al. ${ }^{55}$ reported successful encapsulation of both BSA and silica nanoparticles within PEG-PHPMA vesicles prepared at $20{ }^{\circ} \mathrm{C}$ using a photoinitiated PISA formulation. However, compared to the present study, only limited characterization of the extent of encapsulation was undertaken.

\section{CONCLUSIONS}

In summary, we report the in situ encapsulation of silica nanoparticles within PGMA-PHPMA diblock copolymer vesicles prepared via PISA in concentrated aqueous solution. Excess silica is readily removed via centrifugation-redispersion cycles, and the presence of the silica nanoparticles within the purified vesicles is confirmed by cryo-TEM studies. Thermogravimetric analysis enables the loading efficiency to be directly determined, and these results are fully consistent with quantitative data derived from both disk centrifuge sedimentometry and small angle X-ray scattering studies. The former technique indicates that silica encapsulation leads to a density distribution being superimposed on the vesicle size distribution, 
which results in its artificial broadening. The latter technique required development of a new analytical model to calculate the silica volume fraction within the vesicles. SAXS studies also reveal a silica structure factor, which provides compelling evidence for successful nanoparticle encapsulation within the vesicles. To our knowledge, this is the most detailed study yet of a model vesicle encapsulation system. Moreover, we demonstrate that the encapsulated silica nanoparticles can be released in a controlled manner via thermally triggered vesicle dissociation. Time-resolved SAXS studies indicated that the vesicle-to-sphere morphological transition is complete after 12 min at $0{ }^{\circ} \mathrm{C}$. DLS studies and TEM images show that this morphological transition required much longer time scales (hours/days) when cooling to 2 , 5, or $10{ }^{\circ} \mathrm{C}$. Our findings suggest the possibility of a "self-healing" formulation for synthetic hydrogels and perhaps also biological tissue. ${ }^{40}$ Furthermore, we demonstrate that in situ vesicle loading via PISA formulations is translatable to other cargoes, including biologically relevant species such as proteins.

\section{ASSOCIATED CONTENT}

\section{S Supporting Information}

The Supporting Information is available free of charge on the ACS Publications website at DOI: 10.1021/jacs.5b10415.

Full details of synthetic protocols and characterization techniques, DCP, TGA, and fluorometer calculations, DMF GPC traces, ${ }^{1} \mathrm{H}$ NMR spectra, additional TEM images, TGA traces, $[\text { silica }]_{s}$ data, SAXS patterns and data fits for the silica sols and a control sample, summary table of SAXS parameters, DLS data, fluorescence emission spectra and calibration plot, and $[\mathrm{BSA}]_{\mathrm{s}}$ data (PDF)

\section{AUTHOR INFORMATION}

\section{Corresponding Authors}

*cmable1@sheffield.ac.uk

*o.mykhaylyk@sheffield.ac.uk

*s.p.armes@sheffield.ac.uk

\section{Notes}

The authors declare no competing financial interest.

\section{ACKNOWLEDGMENTS}

We thank Christopher Hill and Svetomir Tzokov at the University of Sheffield Biomedical Science Electron Microscopy Suite. The authors are grateful to ESRF (Grenoble, France) for providing SAXS beam time, and the personnel of the ID02 station are thanked for help with SAXS experiments. S.P.A. thanks the European Research Council for an ERC Advanced Investigator grant (PISA 320372) to support C.J.M., O.O.M., B.M. and also EPSRC for a Platform grant (EP/J007846/1) to support O.O.M.

\section{REFERENCES}

(1) Stano, P.; Carrara, P.; Kuruma, Y.; Pereira de Souza, T.; Luisi, P. L. I. Mater. Chem. 2011, 21, 18887.

(2) Li, M.; Harbron, R. L.; Weaver, J. V. M; Binks, B. P.; Mann, S. Nat. Chem. 2013, 5, 529.

(3) Pohorille, A.; Deamer, D. Trends Biotechnol. 2002, 20, 123.

(4) Szostak, J. W.; Bartel, D. P.; Luisi, P. L. Nature 2001, 409, 387.

(5) Stadler, B.; Price, A. D.; Chandrawati, R.; Hosta-Rigau, L.;

Zelikin, A. N.; Caruso, F. Nanoscale 2009, 1, 68.

(6) Nii, T.; Ishii, F. Int. I. Pharm. 2005, 298, 198.
(7) Schwartz, L.; Wolf, D.; Markus, A.; Wybraniec, S.; Wiesman, Z. I. Agric. Food Chem. 2003, 51, 5972.

(8) Shirley, I. M.; Scher, H. B.; Perrin, R. M.; Wege, P. J.; Rodson, M.; Chen, J.-L.; Rehmke, A. W. Pest Manage. Sci. 2001, 57, 129.

(9) Keen, P. H. R.; Slater, N. K. H.; Routh, A. F. Langmuir 2014, 30, 1939.

(10) Yow, H. N.; Routh, A. F. Langmuir 2009, 25, 159.

(11) Torchilin, V. P. Nat. Rev. Drug Discoverv 2005, 4, 145.

(12) Antonietti, M.; Forster, S. Adv. Mater. 2003, 15, 1323.

(13) Discher, B. M.; Won, Y. Y.; Ege, D. S.; Lee, J. C. M.; Bates, F. S.; Discher, D. E.; Hammer, D. A. Science 1999, 284, 1143.

(14) Chécot, F.; Lecommandoux, S.; Gnanou, Y.; Klok, H.-A. Angew. Chem. Int. Ed. 2002, 41, 1339.

(15) Rodríguez-Hernández, J.; Lecommandoux, S. I. Am. Chem. Soc 2005, 127, 2026.

(16) Discher, D. E.; Eisenberg, A. Science 2002, 297, 967.

(17) Du, J.; Tang, Y.; Lewis, A. L.; Armes, S. P. I. Am. Chem. Soc. 2005, 127, 17982.

(18) Wilson, D. A.; Nolte, R. J. M.; van Hest, J. C. M. Nat. Chem. 2012, 4, 268.

(19) Napoli, A.; Valentini, M.; Tirelli, N.; Muller, M.; Hubbell, J. A. Nat. Mater. 2004, 3, 183.

(20) Photos, P. J.; Bacakova, L.; Discher, B.; Bates, F. S.; Discher, D. E. I. Controlled Release 2003, 90, 323.

(21) Brinkhuis, R. P.; Rutjes, F.; van Hest, J. C. M. Polvm. Chem. 2011, 2, 1449.

(22) Pegoraro, C.; Cecchin, D.; Gracia, L. S.; Warren, N.; Madsen, J.; Armes, S. P.; Lewis, A.; MacNeil, S.; Battaglia, G. Cancer Lett. 2013, 334, 328.

(23) Sanson, C.; Schatz, C.; Le Meins, J. F.; Soum, A.; Thevenot, J.; Garanger, E.; Lecommandoux, S. I. Controlled Release 2010, 147, 428

(24) Ahmed, F.; Pakunlu, R. I.; Srinivas, G.; Brannan, A.; Bates, F.; Klein, M. L.; Minko, T.; Discher, D. E. Mol. Pharmaceutics 2006, 3, 340.

(25) Christian, D. A.; Cai, S.; Bowen, D. M.; Kim, Y.; Pajerowski, J. D.; Discher, D. E. Eur. I. Pharm. Biopharm. 2009, 71, 463.

(26) Huang, J.; Bonduelle, C.; Thévenot, J.; Lecommandoux, S.; Heise, A. I. Am. Chem. Soc. 2012, 134, 119.

(27) Lomas, H.; Canton, I.; MacNeil, S.; Du, J.; Armes, S. P.; Ryan, A. J.; Lewis, A. L.; Battaglia, G. Adv. Mater. 2007, 19, 4238.

(28) van Dongen, S. F. M.; Nallani, M.; Cornelissen, J.; Nolte, R. J. M.; van Hest, J. C. M. Chem. - Eur. I. 2009, 15, 1107.

(29) Canton, I.; Massignani, M.; Patikarnmonthon, N.; Chierico, L.; Robertson, J.; Renshaw, S. A.; Warren, N. J.; Madsen, J. P.; Armes, S. P.; Lewis, A. L.; Battaglia, G. FASEB I. 2013, 27, 98.

(30) Lecommandoux, S.; Sandre, O.; Chécot, F.; RodriguezHernandez, J.; Perzynski, R. L. Magn. Magn. Mater. 2006, 300, 71.

(31) Fielding, L. A.; Derry, M. J.; Ladmiral, V.; Rosselgong, J.; Rodrigues, A. M.; Ratcliffe, L. P. D.; Sugihara, S.; Armes, S. P. Chemical Science 2013, 4, 2081.

(32) Fielding, L. A.; Lane, J. A.; Derry, M. J.; Mykhaylyk, O. O.; Armes, S. P. I. Am. Chem. Soc. 2014, 136, 5790.

(33) Gonzato, C.; Semsarilar, M.; Jones, E. R.; Li, F.; Krooshof, G. J. P.; Wyman, P.; Mykhaylyk, O. O.; Tuinier, R.; Armes, S. P. I.Am. Chem. Soc. 2014, 136, 11100.

(34) Sugihara, S.; Blanazs, A.; Armes, S. P.; Ryan, A. J.; Lewis, A. L. I. Am. Chem. Soc. 2011, 133, 15707.

(35) Blanazs, A.; Madsen, J.; Battaglia, G.; Ryan, A. J.; Armes, S. P. I. Am. Chem. Soc. 2011, 133, 16581.

(36) Blanazs, A.; Ryan, A. J.; Armes, S. P. Macromolecules 2012, 45, 5099.

(37) Warren, N. J.; Armes, S. P. I. Am. Chem. Soc. 2014, 136, 10174.

(38) Warren, N. J.; Mykhaylyk, O. O.; Ryan, A. J.; Williams, M.; Doussineau, T.; Dugourd, P.; Antoine, R.; Portale, G.; Armes, S. P. I. Am. Chem. Soc. 2015, 137, 1929.

(39) We are aware of a single report describing the in situ encapsulation of a model hydrophobic dye (Nile Red) within diblock copolymer vesicles using a PISA formulation (see Karagoz, B.; Boyer, C.; Davis, T. P. Macromol. Rapid Commun. 2014, 35, 417). However, 
styrene monomer conversions of only $10 \%$ were obtained, and this study utilized an alcoholic formulation, which has limited applicability for drug delivery. It was also not clear from the reported fluorescence spectroscopy data whether some (or all) of the dye was located within the vesicle membrane rather than the vesicle lumen. Moreover, encapsulation efficiencies of up to $120 \%$ were claimed, which suggests either an experimental artifact or rather large systematic errors. In contrast, in the present study we focus on an aqueous PISA formulation, achieve very high monomer conversions (99\%), and calculate physically realistic encapsulation efficiencies for silica nanoparticles using three analytical techniques.

(40) Rose, S.; Prevoteau, A.; Elziere, P.; Hourdet, D.; Marcellan, A.; Leibler, L. Nature 2014, 505, 382.

(41) Li, Y.; Armes, S. P. Angew. Chem., Int. Ed. 2010, 49, 4042.

(42) Adams, D. J.; Adams, S.; Atkins, D.; Butler, M. F.; Furzeland, S. L. Controlled Release 2008, 128, 165.

(43) Fielding, L. A.; Mykhaylyk, O. O.; Armes, S. P.; Fowler, P. W.; Mittal, V.; Fitzpatrick, S. Langmuir 2012, 28, 2536.

(44) Balmer, J. A.; Mykhaylyk, O. O.; Schmid, A.; Armes, S. P.; Fairclough, J. P. A.; Ryan, A. I. Langmuir 2011, 27, 8075.

(45) Bang, J.; Jain, S. M.; Li, Z. B.; Lodge, T. P.; Pedersen, J. S.; Kesselman, E.; Talmon, Y. Macromolecules 2006, 39, 1199.

(46) Pedersen, J. S. Adv. Colloid Interface Sci. 1997, 70, 171.

(47) Kinning, D. J.; Thomas, E. L. Macromolecules 1984, 17, 1712.

(48) Ilavsky, J.; Jemian, P. R. I. Appl. Crystallogr. 2009, 42, 347.

(49) Fetters, L. J.; Lohse, D. J.; Colby, R. H. In Phvsical Properties of Polvmers Handbook; Mark, J., Ed.; Springer: New York, 2007; p 447.

(50) Papadopoulou, A.; Green, R. J.; Frazier, R. A. I. Agric. Food Chem. 2005, 53, 158.

(51) Han, X.-L.; Tian, F.-F.; Ge, Y.-S.; Jiang, F.-L.; Lai, L.; Li, D.-W.; Yu, Q.-L.; Wang, J.; Lin, C.; Liu, Y. I. Photochem. Photobiol., B 2012, $109,1$.

(52) Bontempo, D.; Heredia, K. L.; Fish, B. A.; Maynard, H. D. I. Am. Chem. Soc. 2004, 126, 15372.

(53) Mantovani, G.; Lecolley, F.; Tao, L.; Haddleton, D. M.; Clerx, J.; Cornelissen, J. J. L. M.; Velonia, K. I. Am. Chem. Soc. 2005, 127, 2966.

(54) Geng, J.; Mantovani, G.; Tao, L.; Nicolas, J.; Chen, G.; Wallis, R.; Mitchell, D. A.; Johnson, B. R. G.; Evans, S. D.; Haddleton, D. M. L. Am. Chem. Soc. 2007, 129, 15156.

(55) Tan, J.; Sun, H.; Yu, M.; Sumerlin, B. S.; Zhang, L. $\underline{\text { ACS Macro }}$ Lett. 2015, 4, 1249. 